\title{
SALPINGITIS ISTHAMICA NODOSA- A RARE CAUSE OF FEMALE INFERTILITY: A CASE REPORT
}

Vinayaka U. S1, Indumathi D. Mallya², Prashanth Mallya ${ }^{3}$, Ayashath Samsheena ${ }^{4}$

\section{HOW TO CITE THIS ARTICLE:}

Vinayaka U. S, Indumathi D. Mallya, Prashanth Mallya, Ayashath Samsheena. "Salpingitis Isthamica Nodosa- A Rare Cause of Female Infertility: A Case Report". Journal of Evolution of Medical and Dental Sciences 2015; Vol. 4, Issue 62, August 03; Page: 10876-10878, DOI: 10.14260/jemds/2015/1571

CASE REPORT: We present a rare case of case of salpingitis isthamica nodosa diagnosed with hysterosalpingogram (HSG) which was done as a part of work up for female infertility.

A 32 years old female presented to gynaecologist for infertility work up after three years of married life. No history of any previous pelvic illness or tuberculosis or endometriosis. No history of previous surgery or invasive tests and investigations. No abnormality was detected in general physical examination. Pelvic examination was unremarkable. Ultrasound scan of abdomen was performed, which showed normal appearing anteverted uterus with normal myometrium and endometrial thickness of $7 \mathrm{mms}$. Both ovaries were normal. There was no adnexal mass or collection and there was no free fluid in cul-de-sac.

As a part of further work up of female infertility, HSG was performed. The study showed multiple nodular diverticular spaces involving the proximal two-thirds of the fallopian tubes bilaterally, more so on right side. The endometrial cavity also showed irregularity of the endometrial mucosa. There was no spillage of contrast from the fallopian tubes through the fimbrial ends on both sides, suggesting bilateral tubal block.

DISCUSSION: Infertility is an important medico-social issue in developing countries like India. The exact incidence of infertility is never assessed, but is estimated to be about $25 \%$ of the couples of reproductive age in various degrees of severity.[1,2,3] Among these cases of infertility, the incidence of female infertility is about $12-14 \% \cdot{ }^{[4]}$

Salpingitis Isthmica Nodosa (SIN) is a condition of nodular thickening of the proximal fallopian tube enclosing cystically dilated glands trapped in muscular layer. It commonly occurs in the age group of 25 -50 years women with average age at diagnosis being 30 years. ${ }^{[5,6]}$

It is commonly occurs on both the sides. The usual clinical presentation is either infertility or recurrent ectopic gestations. Hysterosalpingography is the imaging modality of choice for Salpingitis isthamica nodosa, which shows fine tiny diverticulae of the fallopian tubes with or without irregular endometrial cavity. The actual incidence of the condition is not known, but estimated to be in the range of $2 \%$ to $11 \%$ of females of reproductive age. The actual incidence is not known as some of the patients will conceive and never undergo HSG.[7] The etiology \& pathogenesis of salpingitis isthamica nodosa is uncertain. It is thought to be an inflammatory process similar to adenomyosis with or without chronic inflammatory process. It is also associated with chronic infection,tubal spasm. ${ }^{8]}$

Karasick at all have found that salpingitis isthamica nodosa is seen in about $10 \%$ of cases of HSG done for evaluation of female infertility. The most common location if the condition is proximal parts of tubes, though it is known to occur in distal ends also. ${ }^{[9]} \mathrm{Homm}$ at all have done a retrospective study, which concluded that the incidence of ectopic gestation is more common in patients with salpingitis isthamica nodosa.[10] 
CONCLUSION: Infertility is one of the important medico-social issue. Salpingitis isthamica nodosa is a medical condition of uncertain etiology is one of the contributing cause of female infertility. HSG is the diagnositic imaging modality for visualisation of tubes, being done in the process of work up of female infertility gives conclusive evidence of the disease. The HSG diagnosis of salpigitis isthamica nodosa is useful for further treatment of infertility.

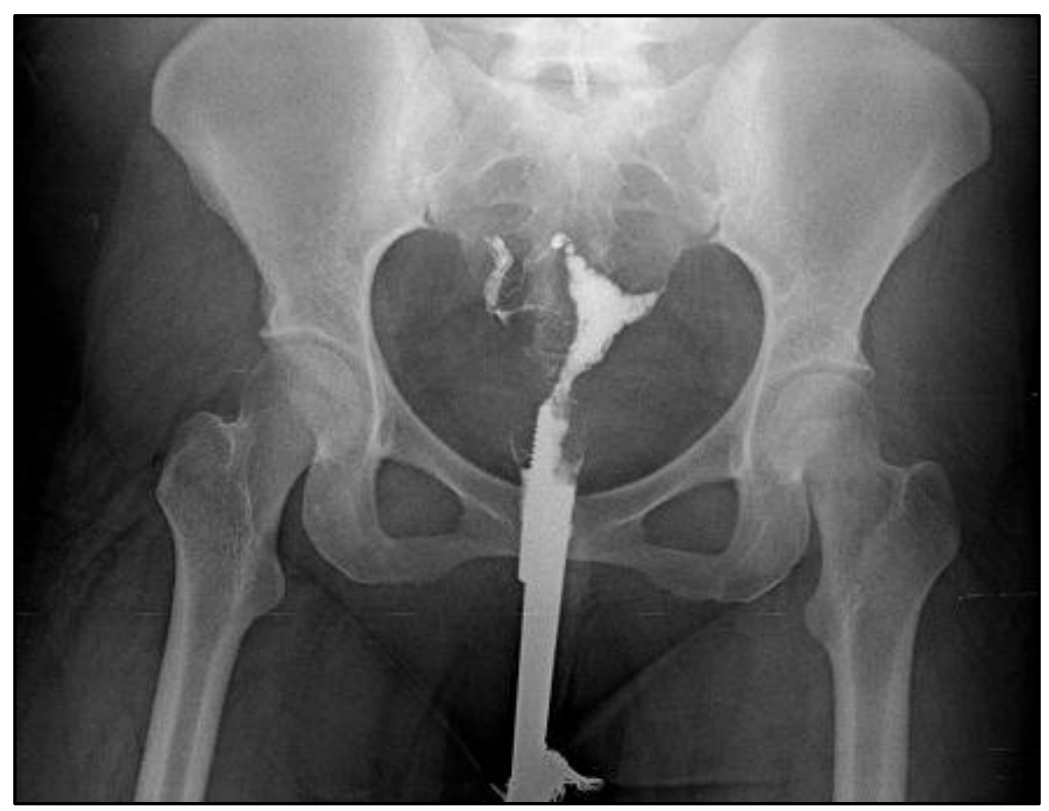

\section{Hysterosalpingogram showing Salpingitis isthamica nodosa}

\section{REFERENCES:}

1. Infecundity, infertility, and childlessness in developing countries. DHS Comparative Reports No 9.Calverton, Maryland, USA: ORC Macro and the World Health Organization; 2004. World Health Organization.

2. Mascarenhas MN, Flaxman SR, Boerma T, Vanderpoel S, Stevens GA (2012) National, Regional, and Global Trends in Infertility Prevalence Since 1990: A Systematic Analysis of 277 Health Surveys. PLoS Med 9(12): e1001356.

3. Vinayaka U. S, Devadasa Acharya K, Arafat M. Haris, Ajamal Shad C. M, Ravichandra G. "Correlation Between Testicular Volume \& Sperm Count in Infertile South Indian Male Patients". Journal of Evolution of Medical and Dental Sciences 2014; Vol. 3, Issue 36, August 18; Page: 9478-9483, DOI: 10.14260/jemds/2014/3223.

4. Ajeet Vasant Saoji,at all; primary infertility problems among female have been a source of concern in india lately, Innovative Journal of Medical and Health Science 4: 1 Jan - Feb(2014) 332-340).

5. Jenkins CS, Williams SR, Schmidt GE. Salpingitis isthmica nodosa: A review of literature, discussion of clinical significance and consideration of patient management. Fertil Steril. 1993; 60: 599-607.

6. Majumdar B, Henderson PH, Semple E. Salpingitis isthmica nodosa: A high risk for tubal pregnancy. Obstet Gynecol Surv. 1983; 62: 73-78. 


\section{CASE REPORT}

7. Chawla N, Kudesia S, Azad S, Singhal M. Salpingitis isthmica nodosa. Ind J Pathol Microbiol. 2009; 52: 434- 35.

8. Creasy JL, Clark RL, Cuttino JT, Groff TR. Salpingitis isthmica nodosa: Radiologic and clinical corelates. Radiology. 1985; 154: 597-600.

9. Karasick S, Karasick D, Schilling J. Salpingitis isthmicanodosa in female infertility.J Can Assoc Radiol. 1985; 36: 118-21.

10. Homm RJ, Holtz G, Garvin AJ. Isthamic ectopic pregnancy and salpingitis isthmica nodosa. Fertile Steril. 1987; 48: 756-6.

\section{AUTHORS:}

1. Vinayaka U.S.

2. Indumathi D. Mallya

3. Prashanth Mallya

4. Ayashath Samsheena

\section{PARTICULARS OF CONTRIBUTORS:}

1. Associate Professor Department of Radiology, Yenepoya Medical College \& Hospital.

2. Consultant Gynaecologist, Yenepoya Hospital. Mangalore. Karnataka.

3. Consultant Anasthesiologist, Yenepoya Hospital. Mangalore. Karnataka.

FINANCIAL OR OTHER COMPETING INTERESTS: None
4. Postgraduate, Department of Radiology, Yenepoya Medical College \& Hospital.

\section{NAME ADDRESS EMAIL ID OF THE} CORRESPONDING AUTHOR:

Dr. Vinayaka U. S,

Associate Professor,

Department of Radiology,

Yenepoya Medical College,

Mangalore-575018,

Dakshina Kannada, Karnataka.

E-mail: drvinayaka@yahoo.com

Date of Submission: 13/06/2015.

Date of Peer Review: 15/06/2015.

Date of Acceptance: 13/07/2015.

Date of Publishing: 03/08/2015. 